\title{
Modes, mechanisms and evidence of bet hedging in rotifer diapause traits
}

\author{
Eduardo M. García-Roger (D) \\ María José Carmona $\cdot$ Manuel Serra
}

Received: 30 October 2015/Revised: 3 June 2016/ Accepted: 9 June 2016/Published online: 21 June 2016

(C) Springer International Publishing Switzerland 2016

\begin{abstract}
In this contribution, we review our knowledge on bet-hedging strategies associated with rotifer diapause. First, we describe the ecological scenario under which bet hedging is likely to have evolved in three diapause-related traits in monogonont rotifer populations: (1) the timing of sex (because diapausing eggs are produced via sexual reproduction), (2) the sexual reproduction ratio (i.e. the fraction of sexually reproducing females) and (3) the timing of diapausing egg hatching. Then, we describe how to discriminate among bet-hedging modes and discuss which modes and mechanisms better fit the variability observed in these traits in rotifers. Finally, we evaluate the strength of the empirical evidence for bet hedging in the scarce studies available, and we call for the need of research at different levels of biological complexity to fully understand bet hedging in rotifer diapause.
\end{abstract}

Keywords Bet hedging - Diapause $\cdot$ Rotifers · Unpredictability

Guest editors: M. Devetter, D. Fontaneto, C. D. Jersabek, D. B. Mark Welch, L. May \& E. J. Walsh / Evolving rotifers, evolving science

E. M. García-Roger $(\bowtie) \cdot$ M. J. Carmona · M. Serra Institut Cavanilles de Biodiversitat i Biologia Evolutiva, Universitat de València, A.O. 22085, 46071 Valencia, Spain

e-mail: eduardo.garcia@uv.es

\section{Introduction}

Monogonont rotifers typically inhabit time-varying habitats and produce diapausing eggs to overpass recurrent adverse periods between favourable planktonic growing seasons (Ricci, 2001; Schröder, 2005). Diapausing eggs are the only link between one season and the next; therefore, the number of diapausing eggs produced at the end of a growing season is typically considered the appropriate measure of fitness in rotifer clonal lineages (Serra \& King, 1999; Serra et al., 2004; Campillo et al., 2011). Interestingly, many rotifer populations from temperate latitudes live in temporary habitats (Walsh et al., 2014), which are often characterized by year-to-year fluctuations in the length of the planktonic growing season (García-Roger et al., 2014). The end of the growing season may be related to changes in the physical environment (e.g. presence/ absence of water) or in biotic factors (e.g. presence/ absence of competitors or predators), and it imposes habitat regimes for rotifers. These regimes vary from highly predictable (i.e. when the length of the growing season extends regularly among seasons) to highly unpredictable (i.e. when there is great among-season variance in the length of the growing season). Such unpredictability may occasionally lead to a failure in the production of a new cohort of diapausing eggs (for example, if the length of the growing season is unexpectedly short), i.e. a zero-fitness event (Martínez-Ruiz \& García-Roger, 2015). Under these circumstances, one of a variety of bet hedging strategies in 
diapause-related traits may be selected to avoid the risk of complete reproductive failure in any generation.

Almost without exception, the production of diapausing eggs is coupled with sexual reproduction in monogonont rotifers (Gilbert \& Schreiber, 1998; Ricci, 2001; Schröder, 2005). Sexual reproduction is initiated by the appearance of sexual females followed by male production, insemination and diapausing egg production. After revisiting the existing rotifer literature, we found that bet hedging has been proposed to evolve in at least three diapause-related traits: (1) the timing of sex, which in practice is used as a proxy of the timing of diapausing egg production and typically measured as the population density threshold for sexual reproduction initiation (i.e. the lowest the threshold, the earliest the timing of sex; Carmona et al., 1995; Schröder \& Gilbert, 2004; Serra et al., 2004; Schröder, 2005; Carmona et al., 2011); (2) the sexual reproduction ratio (best known as the mixis ratio and computed as the fraction of sexually reproducing females in the population) (Gilbert, 2003; Fussmann et al., 2007; Gilbert \& Schröder, 2007) and (3) the timing of diapausing egg hatching (i.e. the fraction of diapausing eggs hatching at the beginning of a new growing season) (Schröder, 2005; García-Roger et al., 2014). However, because bethedging traits must fulfil a set of conditions (see below) and there are various possible modes of bet hedging (Oloffson et al., 2009; Childs et al., 2010), the proper identification of the above-mentioned traits as bet-hedging traits is still uncertain.

\section{Modes of bet hedging and strength of evidence of candidate bet-hedging traits}

Theoreticians distinguish between two basic modes of bet hedging (for review, see Childs et al., 2010), which are typically referred to as conservative and diversified bet hedging (Seger \& Brockmann, 1987; Philippi \& Seger, 1989). These modes result from risk avoidance at the individual level or risk spreading among related individuals of the same genotype, respectively. Under conservative bet hedging, an individual sacrifices expected fitness to reduce temporal variance in reproductive success by employing a single, generalist strategy across all possible environmental scenarios (Philippi \& Seger, 1989; Simons \& Johnston, 2003). On the other hand, diversified bet hedging is conceived as a trans-generational effect that occurs when a single 'genetic' individual-say a genotype or a rotifer clonal lineage-produces different phenotypes in its offspring in advance of future unpredictable conditions (Simons, 2011). At least two sub-modalities are possible for diversified bet-hedging strategies (Childs et al., 2010). These sub-modalities differ on whether diversification occurs within a cohort (i.e. among the offspring derived from one genotype during a single reproductive event) or among cohorts (i.e. when parents vary the characteristics of their offspring stochastically across reproductive events in what is called 'adaptive coin-flipping' bet hedging). It is worth to noting that both strategies involve risk spreading among the offspring of a single genotype.

To invoke bet hedging, either conservative or diversified, a candidate trait is required to reduce temporal variance in fitness across generations at the expense of decreasing the arithmetic mean of fitness. By doing so, the candidate bet-hedging trait would maximize the geometric mean of fitness (Gillespie, 1974; Childs et al., 2010; Starrfelt \& Kokko, 2012). Therefore, bet-hedging traits are apparently sub-optimal under the averaged environmental conditions, but they are adaptive over long time scales. Although this can be seen as a simple condition, empirical assessments of bet hedging are infrequent because quantitative tests of optimality are required across temporal sequences of environmental changes, which is still a challenge (Simons, 2011).

Claims of bet hedging in diapause-related traits are scarce but not rare in the rotifer literature (GarcíaRoger et al., 2014). After a search in the Thomson ISI Web of Science ${ }^{\circledR}$ using combinations of title and topic searches that included '(bet hedg* OR bet-hedg*) AND (rotifer*) AND (diapaus* OR resting egg) AND (sex* OR mixis)', we found a total of 16 records for the period 1970-2014. However, the putative bet hedging in these records was not always supported by adequate tests. Interestingly, Simons (2011) has recently suggested an ordinal scale of six categories to define increasing levels of empirical evidence in candidate bet-hedging traits, which were adapted to whether studies are performed at the within- or among-population level (Table 1). The categories are cumulative in the sense that each category includes the criteria from the previous ones.

Next, we discuss which bet-hedging mode better fits the variability observed in the three diapauserelated rotifer traits mentioned above. We also discuss 
Table 1 Categories of empirical evidence for candidate bet-hedging traits, modified from Simons (2011)

\begin{tabular}{|c|c|c|}
\hline Category & Within-population level & Among-population level \\
\hline I & Recognition of a candidate bet-hedging trait & Recognition of a candidate bet-hedging trait \\
\hline $\mathrm{II}_{\mathrm{a}}$ & $\begin{array}{l}\text { Observation of unpredictable variation at any environmental } \\
\text { factor }\end{array}$ & $\begin{array}{l}\text { Observation of unpredictable variation at any } \\
\text { environmental factor differing across habitats }\end{array}$ \\
\hline $\mathrm{II}_{\mathrm{b}}$ & $\begin{array}{l}\text { Existence of within-genotype phenotypic variability in the } \\
\text { candidate bet-hedging trait }\end{array}$ & Population differentiation in trait expression \\
\hline III & $\mathrm{II}_{\mathrm{a}}+\mathrm{II}_{\mathrm{b}}$ & $\mathrm{II}_{\mathrm{a}}+\mathrm{II}_{\mathrm{b}}$ \\
\hline IV & $\begin{array}{l}\text { Demonstration of different fitness consequences for the } \\
\text { phenotypes under consideration }\end{array}$ & $\begin{array}{l}\text { Demonstration of different fitness consequences for } \\
\text { population strategies across habitats }\end{array}$ \\
\hline V & $\begin{array}{l}\text { Positive test of a selective advantage of the trait under } \\
\text { unpredictable fluctuating selection regime }\end{array}$ & $\begin{array}{l}\text { Selective advantage of population strategies in respective } \\
\text { habitats }\end{array}$ \\
\hline VI & $\begin{array}{l}\text { Quantitative fit of trait expression to the degree of } \\
\text { unpredictability }\end{array}$ & $\begin{array}{l}\text { Quantitative fit of population strategies to the degree of } \\
\text { unpredictability in respective habitats }\end{array}$ \\
\hline
\end{tabular}

the underlying mechanisms promoting bet hedging and evaluate the strength of evidence in favour of bet hedging for each candidate trait following the criteria proposed by Simons (2011).

\section{The timing of sex}

The timing of sex has been proposed as an instance of the conservative bet-hedging trait in rotifer populations inhabiting unpredictable environments (Carmona et al., 1995; Serra \& King, 1999; Schröder \& Gilbert, 2004; Serra et al., 2004; Gilbert, 2007a). If the end of the growing season-or the nutritional conditions required for diapausing egg production (Gilbert, 2010) — cannot be predicted by rotifers, then producing diapausing eggs as soon as possible can avoid the risk of a zero-fitness event. This strategy may seem sub-optimal because a rotifer clone producing diapausing eggs too early, while favourable conditions still prevail would experience a selective disadvantage because an investment in diapause results in a direct reduction of the current population growth rate (Carmona et al., 2009; Serra \& Snell, 2009). However, clones producing diapausing eggs too late will probably not survive an unexpectedly early end of the growing season. Accordingly, a conservative bethedging clone would overcome the disadvantage of producing, on average, a lower yield of diapausing eggs by reducing the variance in diapausing egg production across growing seasons.
Table 2 summarizes the strength of evidence from tests of bet hedging associated with the timing of sex following Simons' criteria (2011). Although theoretical work supports the advantage of a conservative 'Early sex' strategy in unpredictable habitats (Serra et al., 2004), to the best of our knowledge, no study has yet compared the geometric mean fitness across generations of rotifer clones that differ in their timing of sex, which could be performed in experimentally manipulated planktonic growing seasons of unpredictable length. In the absence of this type of study, evidence for bet hedging in this trait seems restricted and sub-optimal, as it has been observed at the genotype level in qualitative agreement with the expectations from bet-hedging theory.

Although it is not definitive, strong evidence in favour of bet hedging in this trait would arise from population differentiation in the timing of sex associated with a gradient of environmental predictability (i.e. earlier sex as the habitat becomes more unpredictable). Interestingly, a high propensity for sexual reproduction has been reported in a Brachionus calyciflorus Pallas, 1766, population inhabiting a highly unpredictable pond in Patagonia (Gilbert \& Dieguez, 2010). This study reaches up to Category $\mathrm{II}_{\mathrm{a}}$, as it does not hold an among-population comparison. Additionally, several other empirical studies have reported variability in the timing of sex among rotifer populations of different species and from different habitats (Category $\mathrm{II}_{\mathrm{b}}$; Schröder \& Gilbert, 2004; Schröder et al., 2007; Gabaldón \& Carmona, 2015), but they fail to look at the match between this 
Table 2 Categories of bet-hedging evidence in the timing of sex in rotifers

\begin{tabular}{|c|c|c|c|c|}
\hline Category & Description & $\begin{array}{l}\text { Type of } \\
\text { study }\end{array}$ & Species & References \\
\hline I & $\begin{array}{l}\text { Proposal of the timing of sex as a candidate } \\
\text { bet-hedging trait }\end{array}$ & $\mathrm{T}$ & - & $\begin{array}{l}\text { Serra \& King (1999), Gilbert } \\
\text { (2007a) }\end{array}$ \\
\hline \multirow[t]{4}{*}{$\mathrm{II}_{\mathrm{a}}$} & \multirow[t]{3}{*}{$\begin{array}{l}\text { Observation of unpredictable variation in } \\
\text { hydroperiod length in a single habitat }\end{array}$} & \multirow[t]{3}{*}{$\mathrm{W}$} & $\begin{array}{l}\text { B. calyciflorus Pallas, } \\
1766\end{array}$ & Gilbert \& Dieguez (2010) \\
\hline & & & $\begin{array}{l}\text { B. manjavacas } \\
\text { Fontaneto et al., } 2007\end{array}$ & Gabaldón \& Carmona (2015) \\
\hline & & & $\begin{array}{l}\text { B. plicatilis Müller, } \\
1786\end{array}$ & Gabaldón \& Carmona (2015) \\
\hline & $\begin{array}{l}\text { Observation of unpredictable variation in } \\
\text { hydroperiod length across habitats }\end{array}$ & A & B. plicatilis & Franch-Gras et al. (in prep.) \\
\hline \multirow[t]{5}{*}{$\mathrm{II}_{\mathrm{b}}$} & \multirow[t]{5}{*}{ Among-population variability in the timing of sex } & A & $\begin{array}{l}\text { B. angularis Gosse, } \\
1881\end{array}$ & Schröder \& Gilbert (2004) \\
\hline & & A & B. calyciflorus & Schröder \& Gilbert (2004) \\
\hline & & A & E. senta* & $\begin{array}{l}\text { Schröder \& Gilbert (2004), } \\
\text { Schröder et al. (2007) }\end{array}$ \\
\hline & & A & $R$. frontalis & Schröder \& Gilbert (2004) \\
\hline & & A & $\begin{array}{l}\text { Hexarthra spp. } \\
\text { Schmarda, } 1854\end{array}$ & Schröder et al. (2007) \\
\hline
\end{tabular}

Only categories for which there is any type of evidence are presented. Type of study: $T$ theoretical, $A$ among-populations empirical study, $W$ within-population empirical study

* This species is not E. senta sensu stricto, but a species belonging to the E. senta-species complex as described by Schröder \& Walsh (2007)

variability and the degree of environmental unpredictability.

We conclude that evidence for bet hedging in the timing of sex is still weak, likely because of several reasons: (1) many studies often lack accurate measurements for habitat predictability_-due to the fact that appropriate metrics for the organism on focus and long-term monitoring are required (García-Roger et al. 2014), (2) confounding effects such as the possible relationship between growing season length and predictability are not dissected (e.g. a short, but predictable, growing season, would select for early sex too) and (3) the fixation of the long-term optimal strategy can be partially avoided by selection during the clonal growing phase, as each growing season acts as a selective regime (Carmona et al., 2009). In this sense, some studies have reported the existence of genetic (among-clone) variation of the timing of sex within rotifer populations (Aparici et al., 2001; Gilbert, 2002; Carmona et al., 2009; Gabaldón \& Carmona, 2015). The finding of a substantial amount of genetic variation in sex propensity is particularly relevant, given the effect of the timing of sex on individual fitness (reviewed in Serra et al., 2004).

\section{The sexual reproduction ratio}

The sexual reproduction ratio is extremely variable (e.g. Carmona et al., 1994, 1995; Snell \& Boyer, 1988; Gilbert, 2002; Schröder \& Gilbert, 2004; Gilbert \& Schröder, 2007; Carmona et al., 2009). However, despite this variability, the sexual reproduction ratio is almost never $100 \%$, and commonly, it is not higher than $30 \%$; thus, some fraction of the population continues reproducing asexually when sexual reproduction is initiated (Gilbert, 1974; Pourriot \& Clément, 1975; Carmona et al., 1995; Schröder, 2001; Gilbert, 2002; Schröder, 2005). This partial response to the induction of sexual reproduction has been reported at the clone level too, and it is described as an intriguing phenomenon because all females within a clonal lineage and their oocytes are genetically identical (Gilbert, 2003; Gilbert \& Schröder, 
2007; Fussmann et al., 2007). Consequently, intermediate sexual reproduction ratios have been regarded as evidence of a diversified bet-hedging strategy (sensu Seger \& Brockmann, 1987) that would allow for the maintenance of both reproductive modes within a clonal lineage (Serra \& King, 1999). Intermediate sexual reproduction ratios may evolve in unpredictable habitats, where early sex ensures the production of at least some diapausing eggs. It should be noted that an early sex initiation could have a significant cost if the planktonic growing season was to end up being long, but this cost could be reduced if early sex initiation is balanced by an intermediate sexual reproduction ratio. Modelling by Serra et al. (2005) showed that sexual reproduction ratios as low as $14 \%$ maximized diapausing egg production in habitats with unpredictable growing season length. Indeed, such ratio and a threshold of 70 individuals $1^{-1}$ were revealed as an evolutionary stable strategy.

Evidence for bet hedging in the sexual reproduction ratio is summarized in Table 3. This evidence is restricted to the observation of within-genotype variability in the trait (Category $\mathrm{II}_{\mathrm{b}}$ ), which has been reported in a considerable number of rotifer species. Unfortunately, only a single study by Campillo et al. (2011) has focused on among-population variation, but it had no direct measure of the degree of habitat unpredictability.

The description of a proximate mechanism responsible for the within-genotype variation observed in the sexual reproduction ratio is still in progress (Gilbert 2003, 2007a, b; Fussmann et al., 2007). Such an underlying mechanism would help in differentiating between bet-hedging sub-modalities. Sexual offspring production haphazardly varies among females of the same clone in several rotifer species (Gilbert, 2007b; Gilbert \& Schröder, 2007; Fussmann et al., 2007) and among maternal age at the within-female level (Pourriot \& Rougier, 1976; Rougier \& Pourriot, 1977; Pourriot \& Rougier, 1986; Carmona et al., 1994; Gilbert \& Schröder, 2007; Fussmann et al., 2007). The most prevalent pattern here is one of the decreasing propensities to produce sexual offspring with maternal age. Therefore, at least two different mechanisms seem to jointly operate to generate diversification in the reproductive mode of the offspring of rotifer females. In any case, whatever the mechanism underlying this variability in the sexual reproduction ratio (i.e. either 'coin-flipping' or non-genetic maternal effects), a condition for bet hedging is that diversification must be expressed in response to environmental factors without predictive value for the future environment (see Menu \& Desouhant, 2002; Evans \& Dennehy, 2005; Crean \& Marshall, 2009). Currently, this concept has not yet been proved.

\section{The timing of diapausing egg hatching}

Not all rotifer diapausing eggs hatch in the season following their production. Consequently, bet hedging in the timing of diapausing egg hatching has been claimed (Schröder, 2005; García-Roger et al., 2006a). Most of our knowledge on the optimum duration of diapause in rotifers comes from mathematical models (for review see García-Roger et al., 2014), which are mainly inspired by the seminal work by Cohen (1966) on germination in plant seeds. In his original model, Cohen (1966) considered two types of years (favourable vs. adverse) occurring with a certain fixed probability and showed that optimal germination/ hatching rates should be proportional to the probability of experiencing a favourable year. In an ecological scenario where the habitat is unsuitable during periods of varying predictability, a fraction of diapausing eggs is expected to remain in diapause at the beginning of a new planktonic growing season, unresponsive to the environmental stimuli promoting hatching. Thus, this pattern ensures that some eggs will survive in the sediments until the following growing season.

Empirical evidence for bet hedging in the timing of diapausing egg hatching is summarized in Table 4. Beyond the observation of different durations of diapause in diapausing eggs of natural rotifer populations, which forms a very preliminary level of evidence (Category I; see for instance García-Roger et al., 2006b), Schröder (2005) suggested that producing diapausing eggs with more or less prolonged diapauses might be a case of diversified bet hedging if 'Early' (diapausing eggs being ready to hatch immediately after production) and 'Late' (diapausing eggs remaining in diapause in the egg bank) hatchers are produced from the same clone. Interestingly, this author observed that not all diapausing eggs produced from single clones in Epiphanes senta Müller, 1773, Rhinoglena frontalis Ehrenberg, 1853, and B. calyciflorus (Schröder, 1999, 2005) hatched when subjected to a first event of hatching stimulus. Thereafter, in a 
Table 3 Categories of bet-hedging evidence in the sexual reproduction ratio in rotifers

\begin{tabular}{|c|c|c|c|c|}
\hline Category & Description & $\begin{array}{l}\text { Type } \\
\text { of } \\
\text { study }\end{array}$ & Species & References \\
\hline I & $\begin{array}{l}\text { Proposal of intermediate sexual reproduction } \\
\text { ratios as a candidate bet-hedging trait }\end{array}$ & $\mathrm{T}$ & - & Serra \& King (1999), Serra et al. (2004) \\
\hline \multirow[t]{9}{*}{$\mathrm{II}_{\mathrm{b}}$} & \multirow[t]{8}{*}{$\begin{array}{l}\text { Existence of phenotypic variability in the } \\
\text { sexual reproduction ratio at the within- } \\
\text { genotype level }\end{array}$} & W & $\begin{array}{l}\text { N. copeus } \\
\text { Ehrenberg, } \\
1834\end{array}$ & Pourriot \& Clèment (1975) \\
\hline & & W & $\begin{array}{l}\text { A. sieboldi } \\
\text { Leydig, } 1854\end{array}$ & Kabay \& Gilbert (1977) \\
\hline & & W & B. plicatilis & $\begin{array}{l}\text { Hino \& Hirano (1977), Snell \& Boyer } \\
\text { (1988), Carmona et al. (1994) }\end{array}$ \\
\hline & & W & $\begin{array}{l}\text { S. pectinata } \\
\text { Ehrenberg, } \\
1832\end{array}$ & Gilbert \& Schreiber (1998) \\
\hline & & W & B. calyciflorus & $\begin{array}{l}\text { Gilbert (1963, 2002, 2003, 2007b), Gilbert } \\
\text { \& Schröder (2007), Fussmann et al. } \\
(2007)\end{array}$ \\
\hline & & \multirow[t]{3}{*}{$\mathrm{W}$} & B. angularis & Gilbert \& Schröder (2007) \\
\hline & & & $\begin{array}{l}\text { E. ukera } \\
\text { Schröder \& } \\
\text { Walsh, } 2007\end{array}$ & Gilbert \& Schröder (2007) \\
\hline & & & $R$. frontalis & Gilbert \& Schröder (2007) \\
\hline & $\begin{array}{l}\text { Among-population variability in the sexual } \\
\text { reproduction ratio }\end{array}$ & A & B. plicatilis & Campillo et al. (2011) \\
\hline
\end{tabular}

Only categories for which there is any type of evidence are presented. Type of study: $T$ theoretical, $A$ among-populations empirical study, $W$ within-population empirical study

second exposure to identical hatching conditions, a fraction of 'Late' diapausing eggs still hatched. This pattern has been recently observed for $B$. plicatilis Müller, 1786, too (Martínez-Ruiz \& García-Roger, 2015). All these studies provide empirical evidence at the Category $\mathrm{II}_{\mathrm{b}}$ level.

Stronger evidence (Category III) arises from a recent study by García-Roger et al. (2014), in which a significant positive correlation was found between the hatching fraction of diapausing eggs from different $B$. plicatilis populations (initially reported by GarcíaRoger et al., 2006b) and a proxy for predictability of the ponds that these populations inhabit. That proxy was based on the assumed positive relationship between habitat predictability and diversity (Slobodkin \& Sanders, 1969) and only considered a predictability gradient that varied from unpredictable to predictably good habitats. While the pattern found was consistent with theoretical predictions, it is worth noting that the gradient from unpredictable to predictably bad habitats remains unexplored, and more accurate ways of measuring predictability are necessary.

Little is known about the proximate mechanisms that lead to within-genotype variability in the duration of diapause. Martínez-Ruiz \& García-Roger (2015) proposed that diversification in the timing of diapausing egg hatching could occur through the following ways: (1) Each inseminated sexual female within a clone, as a result of an independent reproductive event, may probabilistically produce a single phenotype (all 'Early' or all 'Late', in Schröder's terminology; see Fig. 1a), which would be an instance of the 'adaptive coin-flipping' modality of bet hedging operating at the mother level (Oloffson et al., 2009; Childs et al., 2010). (2) Each inseminated sexual female within a clone may produce resting eggs with different phenotypes ('Early' and 'Late'; see Fig. 1b, c). Note here that the authors considered each insemination as a single reproductive event. 
Table 4 Categories of bet-hedging evidence in the timing of diapausing egg hatching in rotifers

\begin{tabular}{|c|c|c|c|c|}
\hline Category & Description & $\begin{array}{l}\text { Type of } \\
\text { study }\end{array}$ & Species & References \\
\hline I & $\begin{array}{l}\text { Proposal of the duration of diapause as a } \\
\text { candidate bet-hedging trait }\end{array}$ & $\mathrm{T}$ & - & $\begin{array}{l}\text { Schröder (2005), García- } \\
\text { Roger et al. (2006a, 2014) }\end{array}$ \\
\hline $\mathrm{II}_{\mathrm{a}}$ & $\begin{array}{l}\text { Observation of } \\
\text { unpredictable environmental variation } \\
\text { across habitats }\end{array}$ & A & B. plicatilis & García-Roger et al. (2014) \\
\hline \multirow[t]{5}{*}{$\mathrm{II}_{\mathrm{b}}$} & $\begin{array}{l}\text { Existence of phenotypic variability in the } \\
\text { timing of diapausing egg hatching at the } \\
\text { within-genotype level }\end{array}$ & W & $\begin{array}{l}\text { E. senta Müller, } \\
1773\end{array}$ & Schröder (1999) \\
\hline & & W & R. frontalis & Schröder (2005) \\
\hline & & W & B. calyciflorus & Schröder (2005) \\
\hline & & W & B. plicatilis & $\begin{array}{l}\text { Martínez-Ruiz \& García- } \\
\text { Roger (2015) }\end{array}$ \\
\hline & $\begin{array}{l}\text { Among-population variability in the } \\
\text { timing of diapausing egg hatching (i.e. } \\
\text { population differentiation in the } \\
\text { hatching fraction of diapausing eggs) }\end{array}$ & A & B. plicatilis & García-Roger et al. (2006b) \\
\hline III & $\begin{array}{l}\text { Observation of } \\
\text { unpredictable environmental variation } \\
\text { across habitats }+ \text { Population } \\
\text { differentiation in the hatching fraction } \\
\text { of diapausing eggs }\end{array}$ & A & B. plicatilis & García-Roger et al. (2014) \\
\hline
\end{tabular}

Only categories for which there is any type of evidence are presented. Type of study: $T$ theoretical, $A$ among-populations empirical study, $W$ within-population empirical study

Martínez-Ruiz \& García-Roger (2015) tracked the offspring of individual inseminated females from controlled crosses in clonal lineages of $B$. plicatilis and tested for an effect of egg laying order on the hatching phenotype ('Early' vs. 'Late'). These authors have found a significant effect of diapausing egg laying order on the probability of being an 'Early' or 'Late' hatcher expressed at the within-female level, but no differences among females within clones were observed (i.e. all females exhibited the same, but variable, response). This finding supports a diversification mechanism mediated by a non-anticipatory maternal effect.

\section{Remarks}

To date, the level of empirical evidence in favour of bet hedging, according to Simons' criteria (2011), has reached Category III in the timing of diapausing egg hatching, but only Category II has been reached in both the timing of sex and the sexual reproduction ratio. Our review reveals that the studied traits have a low level of support of empirical evidence and that more specific evidence is still needed for all of them. Namely, more evidence is needed for the establishment of fitness consequences associated with the expression of each diapause-related trait (Category IV), the demonstration of selective advantage of the traits studied against nonbet-hedging alternatives under unpredictable regimes (Category V), and the finding of a match between bethedging trait expression and the degree of unpredictability (Category VI).

Empirical studies of bet hedging in other aquatic organisms displaying diapause are also limited in number. Notwithstanding, there are some remarkable cases where the upper category of evidence has been reported (Simons, 2011). Here, we extended the review of Simons (2011) for the period 2010-2015. For this purpose, we used a search engine in the Thomson ISI Web of Science ${ }^{\circledR}$ similar to that described above, only changing the organism under study to cladocerans, copepods and anostracans, respectively. Studies of cyclic parthenogenetic cladocerans were scarce-only three-and paid attention to either the timing of diapause (Cáceres \& Tessier, 2003) or the timing of 


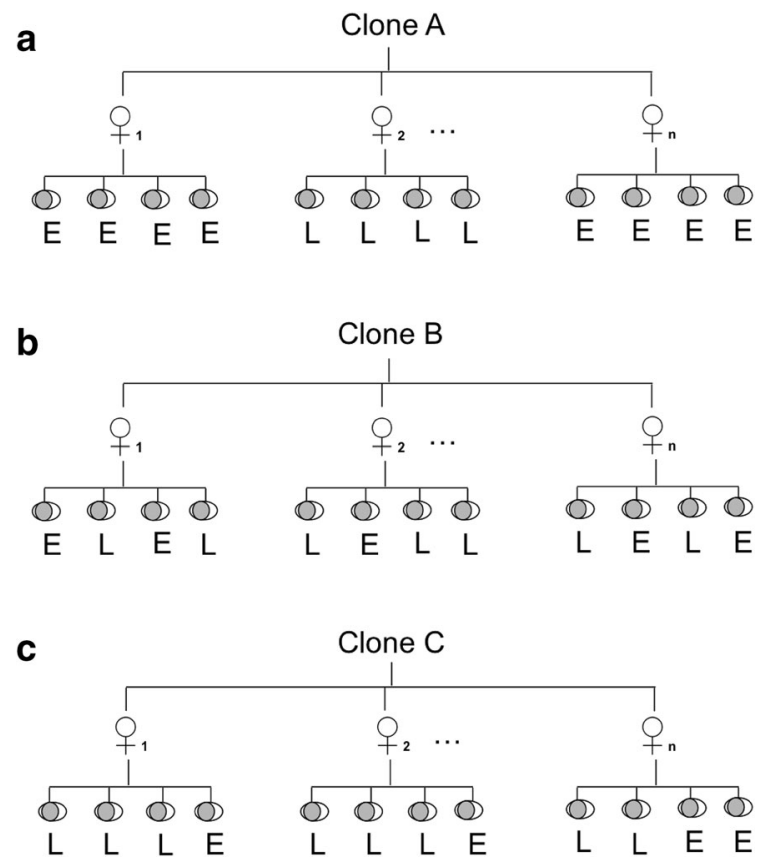

Fig. 1 Modes of diversified bet hedging for the timing of diapausing egg hatching in rotifers. a Diversification occurring among females within the same clone; b diversification haphazardly occurring within the offspring of single females within a clone; and c diversification (E for 'Early' and L for 'Late' hatchers) occurring within the offspring of a single female within a clone following a trend (e.g. a monotonic variation with mother age so that E diapausing eggs are typically produced at advanced laying order)

diapausing egg hatching (De Meester \& De Jager, 1993; Vanoverbeke \& De Meester, 2009). In both cases, the level of empirical evidence met Category $\mathrm{II}_{\mathrm{b}}$. Studies of anostracans typically dealt with the timing of diapausing egg hatching and were most prevalent in Category III (Hildrew, 1985; Saiah \& Perrin, 1990; Simovich \& Hathaway, 1997; Dumont \& Ali, 2004; Vanschoenwinkel et al., 2010), with a remarkable exception in Branchinecta sandiegonensis Fugate, 1993, for which hatching fractions in different populations were found to be optimal given their respective frequency patterns of pool filling, so that Category VI was reached (Philipi et al., 2001). Similarly in copepods, it has been found that the timing of diapausing egg production in Diaptomus sanguineus Forbes, 1876, is in close agreement with a simulation-derived evolutionary stable strategy, thus reaching the highest level of empirical evidence for a conservative bethedging trait (Category VI). This study was however restricted to the analysis of a single population
(Hairston \& Munns, 1984; see also Hairston \& Olds, 1984).

The number of species in which there is any evidence of bet hedging also provides insight into the prevalence of bet hedging in rotifers. Interestingly, while the timing of diapausing egg hatching has reached a higher category than the two other traits, evidence in the first trait is restricted to fewer rotifer species. This result is not surprising because high categories of empirical evidence demand for very challenging and complex studies, which can only be afforded by using a restricted number of adequate model species. In this sense, B. calyciflorus and $B$. plicatilis arise as promising model species for testing bet hedging in diapause-related traits after being studied in 18 out of $30(60 \%)$ assays.

Information on the mechanisms for within-genotype variability needed for diversified bet-hedging traits is also scarce. Gilbert $(2003,2007 b)$ stressed that the oocytes of the same female can develop into either sexual or asexual females, thus making within-genotype diversification possible. However, this phenomenon could be generated by 'adaptive coinflipping' plasticity at the female level mediated by haphazard variation in the physiology of the mother, or it could alternatively be generated by any type of non-haphazard, non-genetic maternal effect (e.g. female age; Carmona et al., 1994; Gilbert \& Schröder, 2007; Fussmann et al., 2007). Notwithstanding, although the phenomenon of intermediate sexual reproduction ratios is puzzling from a mechanistic point of view, it is a clear candidate for diversified bet hedging, as it consists of probabilistic risk spreading among individuals of the same genotype.

In the case of the timing of diapausing egg hatching, the study by Martínez-Ruiz \& García-Roger (2015) points to non-anticipatory maternal effects (see Marshall \& Uller, 2007; Crean \& Marshall, 2009) as the most likely mechanism for diapause duration in rotifers, although other mechanisms of bet hedging contributing to intra-clonal variability cannot be completely ruled out. For instance, 'coin-flipping' could also occur at the embryo level to introduce some noise to the observed maternal-mediated pattern. In this sense, we consider modes and sub-modalities of bet hedging, not as alternatives to explain variability in diapause duration or an incomplete sexual reproduction induction, but as concomitant sources to generate a diverse response. A single trait being able to mediate 
different types of bet hedging has been previously suggested in plants in the case of the timing of flowering, where the evolution of the trait results from a balance between conservative and diversified bethedging components (Rees et al., 2004, 2010; Childs et al., 2010).

Other diapause traits, such as the quantity or quality of diapausing eggs, could also be considered as potential candidate bet-hedging traits. However, we did not obtain any hit after implementing them in our search criteria and so they were not included in this analysis. Egg size can be considered as a proxy of egg quality (i.e. mediated by the amount of reserves). In relation to the evolution of this trait in unpredictable environments, it has been hypothesized a conservative bet hedging consisting in producing eggs larger than would be the optimum in a predictable environment with the same long-term mean quality (Einum \& Fleming, 2004). As mentioned above, to our knowledge, this prediction has not been tested yet in rotifers.

Typically, bet hedging is considered in the context of a single trait. However, in the real world, more than one trait can be involved in the adaptation to environmental unpredictability, as several traits can mediate the same bet-hedging response (Wilbur \& Rudolf, 2006; Childs et al., 2010). For instance, both a conservative bethedging strategy in the timing of sex and a diversified strategy in the duration of diapause likely serve the same objective of avoiding the risk of a complete reproductive failure in habitats with an unpredictable length of the growing season. Because both traits have essentially the same bet-hedging role, it is interesting to ask which should evolve or whether selection of both traits is possible (Wilbur \& Rudolf, 2006). For instance, if the sediments are risky because deterioration in the egg banks is very high (GarcíaRoger et al., 2006a, c), then an early induction of sex to ensure the production of a new cohort of diapausing eggs would be a less costly bet-hedging strategy. In this review, we have identified four rotifer species ( $B$. calyciflorus, B. plicatilis, E. senta and R. frontalis) for which evidence of bet hedging exists in both the timing of sex and the timing of diapausing egg hatching (see Tables 2, 4). However, evaluating the most efficient strategy, or a possible coexistence between traits, requires the assessment of both traits within the same population, which is a condition that has not been accomplished in any species at the moment. Moreover, such assessments should be performed by means of experimental approaches that allow for testing bet hedging at the highest level of empirical evidence (Simons, 2011). From here, we emphasize the need to perform such studies to provide definitive support for the existence of bet hedging in rotifer diapause-related traits in response to year-to-year unpredictability in the planktonic growing season length.

Acknowledgments The research presented in this study was supported by funds from the projects UV-INV-PRECOMP1280525 (University of València, Spain) and CGL2012-30779 (Spanish Ministry of Economy and Competitiveness, cofinanced by UE-FEDER).

\section{References}

Aparici, E., M. J. Carmona \& M. Serra, 2001. Intrapopulation variability for mixis initiation in Brachionus plicatilis. Hydrobiologia 446/447: 45-50.

Cáceres, C. E. \& A. J. Tessier, 2003. How long to rest: the ecology of optimal dormancy and environmental constraint. Ecology 84: 1189-1198.

Campillo, S., E. M. García-Roger, M. J. Carmona \& M. Serra, 2011. Local adaptation in rotifer populations. Evolutionary Ecology 25: 933-947.

Carmona, M. J., A. Gómez \& M. Serra, 1995. Mictic patterns of the rotifer Brachionus plicatilis Müller in small ponds. Hydrobiologia 313(314): 365-371.

Carmona, M. J., M. Serra \& M. R. Miracle, 1994. Effect of population density and genotype on life-history traits in the rotifer Brachionus plicatilis O.F. Müller. Journal of Experimental Marine Biology and Ecology 182: 223-235.

Carmona, M. J., N. Dimas-Flores, E. M. García-Roger \& M. Serra, 2009. Selection of low investment in sex in a cyclically parthenogenetic rotifer. Journal of Evolutionary Biology 22: 1975-1983.

Carmona, M. J., N. Dimas-Flores, J. Montero-Pau \& M. Serra, 2011. Effect of experimental methodology on estimation of density at sex initiation in cyclically parthenogenetic rotifers. Hydrobiologia 662: 131-139.

Childs, D. Z., C. J. E. Metcalf \& M. Rees, 2010. Evolutionary bet-hedging in the real world: empirical evidence and challenges revealed by plants. Proceedings of the Royal Society B: Biological Sciences 277: 3055-3064.

Cohen, D., 1966. Optimizing reproduction in a randomly varying environment. Journal of Theoretical Biology 12: 119-129.

Crean, A. J. \& D. J. Marshall, 2009. Coping with environmental uncertainty: dynamic bet hedging as a maternal effect. Philosophical transactions of the Royal Society B: Biological Sciences 364: 1087-1096.

De Meester, L. \& H. De Jager, 1993. Hatching of Daphnia sexual eggs.1. Intraspecific differences in the hatching responses of Daphnia magna eggs. Freshwater Biology 30: 219-226. 
Dumont, H. J. \& A. J. Ali, 2004. Stage-specific cannibalism and spontaneous cyst hatching in the freshwater fairy shrimp Streptocephalus proboscideus Frauenfeld. Hydrobiologia 524: 103-113.

Einum, S. \& I. A. Fleming, 2004. Environmental unpredictability and offspring size: conservative versus diversified bet-hedging. Evolutionary Ecology Research 6: 443-455.

Evans, M. E. K. \& J. J. Dennehy, 2005. Germ banking: bet hedging and variable release from egg and seed dormancy. The Quarterly Review of Biology 80: 431-451.

Fussmann, G. F., G. Kramer \& M. Labib, 2007. Incomplete induction of mixis in Brachionus calyciflorus: patterns of reproduction at the individual level. Hydrobiologia 593: 111-119.

Gabaldón, C. \& M. J. Carmona, 2015. Allocation patterns in modes of reproduction in two facultatively sexual cryptic rotifer species. Journal of Plankton Research 37: 429-440.

García-Roger, E. M., M. J. Carmona \& M. Serra, 2006a. A simple model relating habitat features to a diapausing egg bank. Limnology and Oceanography 51: 1542-1547.

García-Roger, E. M., M. J. Carmona \& M. Serra, 2006b. Hatching and viability of rotifer diapausing eggs collected from pond sediments. Freshwater Biology 51: 1351-1358.

García-Roger, E. M., M. J. Carmona \& M. Serra, 2006c. Patterns in rotifer diapausing egg bank: density and viability. Journal of Experimental Marine Biology and Ecology 336: 198-210.

García-Roger, E. M., M. Serra \& M. J. Carmona, 2014. Bethedging in diapausing egg hatching of temporary rotifer populations - a review of models and new insights. International Review of Hydrobiology 98: 1-11.

Gilbert, J. J., 1963. Contact chemoreception, mating behaviour, and sexual isolation in the rotifer genus Brachionus. Journal of Experimental Biology 40: 625-641.

Gilbert, J. J., 1974. Dormancy in rotifers. Transcations of the American Microscopical Society 93: 490-513.

Gilbert, J. J., 2002. Endogenous regulation of environmentally induced sexuality in a rotifer: a multigenerational parental effect induced by fertilisation. Freshwater Biology 47: 1633-1641.

Gilbert, J. J., 2003. Environmental and endogenous control of sexuality in a rotifer life cycle: developmental and population biology. Evolution and Development 5: 19-24.

Gilbert, J. J., 2007a. Timing of diapause in monogonont rotifers. In Alekseev, V., J. J. Gilbert \& B. De Stasio (eds), Diapause in Aquatic Invertebrates: Theory and Human Use. Springer, Dordrecht: 11-27.

Gilbert, J. J., 2007b. Induction of mictic females in the rotifer Brachionus: oocytes of amictic females respond individually to population-density signal only during oogenesis shortly before oviposition. Freshwater Biology 52: 1417-1426.

Gilbert, J. J., 2010. Effect of food concentration on the production and viability of resting eggs of the rotifer Brachionus: implications for the timing of sexual reproduction. Freshwater Biology 54: 2437-2446.

Gilbert, J. J. \& D. K. Schreiber, 1998. Asexual diapause induced by food limitation in the rotifer Synchaeta pectinata. Ecology 79: 1371-1381.
Gilbert, J. J. \& T. Schröder, 2007. Intraclonal variation in propensity for mixis in several rotifers: variation among females and with maternal age. Hydrobiologia 593: 121-128.

Gilbert, J. J. \& M. C. Dieguez, 2010. Low crowding threshold for induction of sexual reproduction and diapause in a patagonian rotifer. Freshwater Biology 55: 1705-1718.

Gillespie, J. H., 1974. Natural selection for within-generation variance in offspring number. Genetics 76: 601-606.

Hairston, N. G. \& W. R. Munns, 1984. The timing of copepod diapause as an evolutionary stable strategy. American Naturalist 123: 733-751.

Hairston, N. G. \& E. J. Olds, 1984. Population differences in the timing of diapause in a spatially heterogeneous environment. Oecologia 61: 42-48.

Hildrew, A. G., 1985. A quantitative study of the life-history of a fairy shrimp (Branchiopoda, Anostraca) in relation to the temporary nature of its habitat, a Kenyan rainpool. Journal of Animal Ecology 54: 99-110.

Hino A. \& R. Hirano, 1977. Ecological studies on the mechanism of bisexual reproduction in the rotifer Brachionus plicatilis-II. Effects of cumulative parthenogenetic generation on the frequency of bisexual reproduction. Bull. Jpn. Soc. Sci. Fish. 43: 1147-1155.

Kabay, M. E. \& J. J. Gilbert, 1977. Polymorphism and reproductive mode in the rotifer, Asplanchna sieboldi: relationship between meiotic oogenesis and shape of body-wall outgrowths. Journal of Experimental Zoology 201: 21-28.

Marshall, D. J. \& T. Uller, 2007. When is a maternal effect adaptive? Oikos 116: 1957-1963.

Martínez-Ruiz, C. \& E. M. García-Roger, 2015. Being first increases the probability of long diapause in rotifer resting eggs. Hydrobiologia 745: 111-121.

Menu, F. \& E. Desouhant, 2002. Bet-hedging for variability in life cycle duration: bigger and later-emerging chestnut weevils have increased probability of a prolonged diapause. Oecologia 132: 167-174.

Oloffson, H., J. Ripa \& N. Jonzen, 2009. Bet-hedging as an evolutionary game: the trade-off between egg size and number. Proceedings of the Royal Society B: Biological Sciences 276: 2963-2969.

Philippi, T. \& J. Seger, 1989. Hedging one's evolutionary bets, revisited. Trends in Ecology and Evolution 4: 41-44.

Philipi, T., M. A. Simovich, E. T. Bauder \& J. A. Moorad, 2001. Habitat ephemerality and hatching fractions of a diapausing anostracan (Crustacea: Branchiopoda). Israel Journal of Zoology 47: 387-395.

Pourriot, R. \& P. Clément, 1975. Influence de la durée de l'éclairement quotidien sur le taux de femelles mictiques chez Notommata copeus Ehr. (rotifère). Oecologia 22: 67-77.

Pourriot, R. \& C. Rougier, 1976. Influence de l'âge des parents sur la production de femelles mictiques chez Brachionus calyciflorus (Pallas) et B. rubens Ehr. (Rotifères). Comptes Rendus Hebdomadaires des Séances de l'Académie des Sciences Série D 283: 1497-1500.

Pourriot, R. \& C. Rougier, 1986. Rhythmes de production de femelles sexuées chez le rotifère Brachionus calyciflorus, en élevage à température constante. Bulletin de la Societé Zoologique de France 111: 203-209. 
Rees, M., D. Z. Childs, K. E. Rose \& P. J. Grubb, 2004. Evolution of size dependent flowering in a variable environment: partitioning the effects of fluctuating selection. Proceedings of the Royal Society B: Biological Sciences 271: 471-475.

Rees, M., C. Jessica, E. Metcalf \& D. Z. Childs, 2010. Bethedging as an evolutionary game: the trade-off between egg size and number. Proceedings of the Royal Society B: Biological Sciences 277: 1149-1151.

Ricci, C., 2001. Dormancy patterns in rotifers. Hydrobiologia 446(447): 1-11.

Rougier, C. \& R. Pourriot, 1977. Aging and control of the reproduction in Brachionus calyciflorus (Pallas) (Rotatoria). Experimental Gerontology 12: 137-151.

Saiah, H. \& N. Perrin, 1990. Autumnal vs spring hatching in the fairy shrimp Siphonophanes grubii (Dybowski) (Crustacea, Anostraca) - diversified-bet hedging strategy. Functional Ecology 4: 769-775.

Schröder, T., 1999. Lebenszyklusstrategien planktischer Rotatorien (Monogononta, Rotifera) im Zusammenhang mit den saisonalen Überflutungen in der Flussaue des Unteren Odertals. Ph.D. Dissertation. Freie Universität Berlin, $183 \mathrm{pp}$.

Schröder, T., 2001. Colonizing strategies and diapause of planktonic rotifers (monogononta, rotifera) during aquatic and terrestrial phases in a floodplain (Lower Oder valley, Germany). International Review of Hydrobiology 86: 635-660.

Schröder, T., 2005. Diapause in monogonont rotifers. Hydrobiologia 181: 291-306.

Schröder, T., S. Howard, M. L. Arroyo \& E. J. Walsh, 2007. Sexual reproduction and diapause of Hexarthra sp. (Rotifera) in short-lived ponds in the Chihuahuan Desert. Freshwater Biology 52: 1033-1042.

Schröder, T. \& J. J. Gilbert, 2004. Transgenerational plasticity for sexual reproduction and diapause in the life cycle of monogonont rotifers: intraclonal, intraspecific and interspecific variation in the response to crowding. Functional Ecology 18: 458-466.

Schröder, T. \& E. J. Walsh, 2007. Cryptic speciation in the cosmopolitan Epiphanes senta complex (Monogononta, Rotifera) with the description of new species. Hydrobiologia 593: 129-140.

Seger, J. \& H. J. Brockmann, 1987. What is bet hedging? In Harvey, P. H. \& L. Partridge (eds), Oxford Surveys in Evolutionary Biology. Oxford University Press, Oxford: 182-211.

Serra, M. \& C. E. King, 1999. Optimal rates of bisexual reproduction in cyclical parthenogens with density- dependent growth. Journal of Evolutionary Biology 12: 263-271.

Serra, M. \& T. W. Snell, 2009. Sex loss in monogonont rotifers. In Schön, Isa, Koen Martens \& Peter Van Dijk (eds), Lost Sex. Springer, Berlin.

Serra, M., T. W. Snell \& C. E. King, 2004. The timing of sex in rotifers. In Moya, A. \& E. Font (eds), Evolution from Molecules to Ecosystems. Oxford University Press, New York: 135-146.

Serra, M., T. W. Snell \& J. J. Gilbert, 2005. Delayed mixis in rotifers: an adaptive response to the effects of density-dependent sex on population growth. Journal of Plankton Research 27: 37-45.

Simons, A. M., 2011. Modes of response to environmental change and the elusive empirical evidence for bet hedging. Proceedings of the Royal Society B: Biological Sciences 278: 1601-1609.

Simons, A. M. \& M. O. Johnston, 2003. Suboptimal timing of reproduction in Lobelia inflata may be a conservative bethedging strategy. Journal of Evolutionary Biology 16: 233-243.

Simovich, M. A. \& S. A. Hathaway, 1997. Diversified bethedging as a reproductive strategy of some ephemeral pool anostracans (Branchiopoda). Journal of Crustacean Biology $17: 38-44$.

Slobodkin, L. B. \& H. L. Sanders, 1969. On the contribution of environmental predictability to species diversity. Brookhaven Symposium of Biology 22: 82-95.

Snell, T. W. \& E. M. Boyer, 1988. Thresholds for mictic female production in the rotifer Brachionus plicatilis (Müller). Journal of Experimental Marine Biology and Ecology 124: 73-85.

Starrfelt, J. \& H. Kokko, 2012. Bet-hedging - a triple trade-off between means, variances and correlations. Biological Reviewvs 87: 742-755.

Vanoverbeke, J. \& L. De Meester, 2009. Within season shortterm hatching delays suggest risk-spreading behaviour in populations of the freshwater cladoceran Daphnia. Ecoscience 16: 441-451.

Vanschoenwinkel, B., M. Seaman \& L. Brendonck, 2010. Hatching phenology, life history and egg bank size of fairy shrimp Branchiodopsis spp. (Branchiopoda, Crustacea) in relation to the ephemerality of their rock pool habitat. Aquatic Ecology 44: 771-780.

Walsh, E. J., H. A. Smith \& R. L. Wallace, 2014. Rotifers of temporary waters. International Review of Hydrobiology 99: 3-19.

Wilbur, H. M. \& V. H. W. Rudolf, 2006. Life-history evolution in uncertain environments: bet hedging in time. American Naturalist 168: 398-411. 